\title{
Mid-Latitude Electron Density Enhancement in the Nocturnal Topside Ionosphere and Its Longitudinal Inequalities
}

\author{
Girija RAJARAM* and Tatsuzo OBAyAShi** \\ *Indian Institute of Geomagnetism, Colaba, Bombay, India \\ **Institute of Space and Aeronautical Sciences, University of Tokyo, \\ Tokyo, Japan
}

(Received February 9, 1976; Revised June 3, 1977)

\begin{abstract}
A study of data from the cylindrical electrostatic probe and the topside sounder aboard the Alouette 2 satellite reveals the existence of nighttime $N_{e}$ enhancements at mid-latitudes, at altitudes $1,000-3,000 \mathrm{~km}$. The peaks seem to approach the equator with increasing altitude, and appear to lie on a specific set of geomagnetic field lines. The intensity and location of these nocturnal $N_{e}$ peaks, as well as the electron density in the entire low- to mid-latitude range, show a marked dependence on geomagnetic longitude. These observations are interpreted in terms of field-aligned flow of thermal plasma from the protonosphere above $3,000 \mathrm{~km}$ in the presence of a westward electric field at $L \approx 2$.
\end{abstract}

\section{Introduction and Observations}

The occurrence of an enhanced electron density peak at $\pm 40^{\circ} \phi$ (geomagnetic latitude) in the $1,000 \mathrm{~km}$ altitude region at night has been reported by Brace et al. (1967) from observations of the Explorer 22 satellite. MatuUrA and ONDOH (1969) also observed a similar $N_{e}$ peak from their study of nighttime Alouette 2 topside ionograms; they reported it to be visible only up to the altitude of $1,500 \mathrm{~km}$.

The present work shows that these nocturnal mid-latitude $N_{e}$ peaks are seen at altitudes up to at least $3,000 \mathrm{~km}$ (the apogee height of the Alouette 2 satellite). The feature exhibits a marked dependence on equatorial geomagnetic longitude ( $\lambda$ ), the intensity of the $N_{e}$ peak being strongest in the vicinity of $180^{\circ} \lambda$ and weakest around $0^{\circ} \lambda$. This geomagnetic longitude dependence is also seen in the electron density values at the lower latitudes of 10,20 , and $30^{\circ} \phi$. The data used is from the topside sounder and the in situ cylindrical electrostatic probe aboard the Alouette 2 satellite. Figure 1 shows the latitudinal variation of electron density at constant heights ranging from $400 \mathrm{~km}$ to $2,800 \mathrm{~km}$, over 


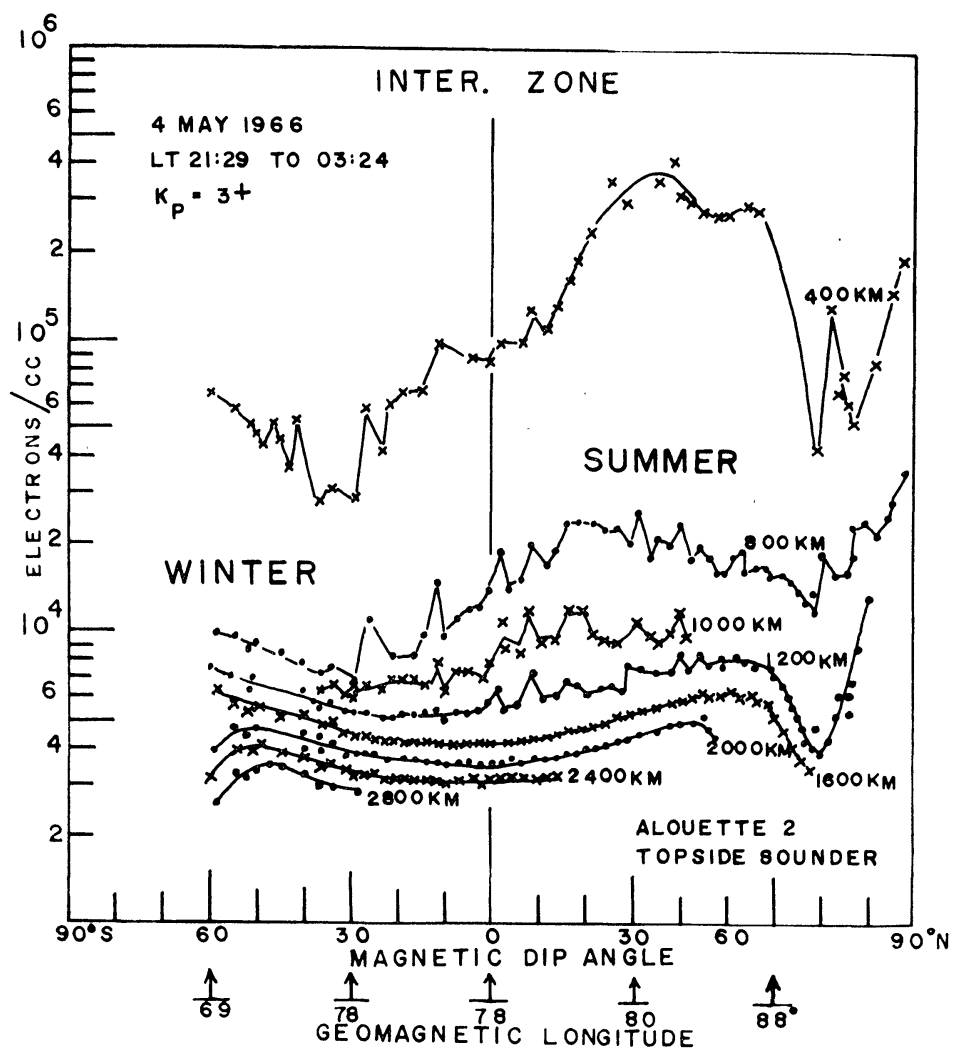

Fig. 1. Latitudinal variation of electron density at constant heights ranging from 400 to $2,800 \mathrm{~km}$ for a May midnight pass of the Alouette 2 .

the Europe-Africa sector, for a May night. The $N_{e}$ distribution between 400 and $1,000 \mathrm{~km}$ is characterised by sharp irregularities which smooth out at higher altitudes. Above $1,200 \mathrm{~km}$ a smooth trough in the electron density forms at the low latitudes, with $N_{e}$ enhancements at around $\pm 55^{\circ}$ dip angle. These midlatitude $N_{e}$ peaks seem to approach the equator with increasing altitude, moving in from about $60^{\circ}$ dip angle at the $1,600 \mathrm{~km}$ level to about $40^{\circ}$ dip angle at higher altitudes.

It was decided to plot the height contours of constant electron density for the same satellite pass together with the geomagnetic lines of force, as shown in Fig. 2. The field lines with feet at $16,23,31,36$, and $41^{\circ}$ dip latitude are marked as $\mathbf{M}_{16}, \mathbf{M}_{23}, \mathbf{M}_{31}, \mathbf{M}_{36}$, and $\mathbf{M}_{41}$ respectively, and are shown by the dashed curves. They are derived on the assumption of a dipole field model from the equation

$$
r=r_{0} \cos ^{2} \theta
$$




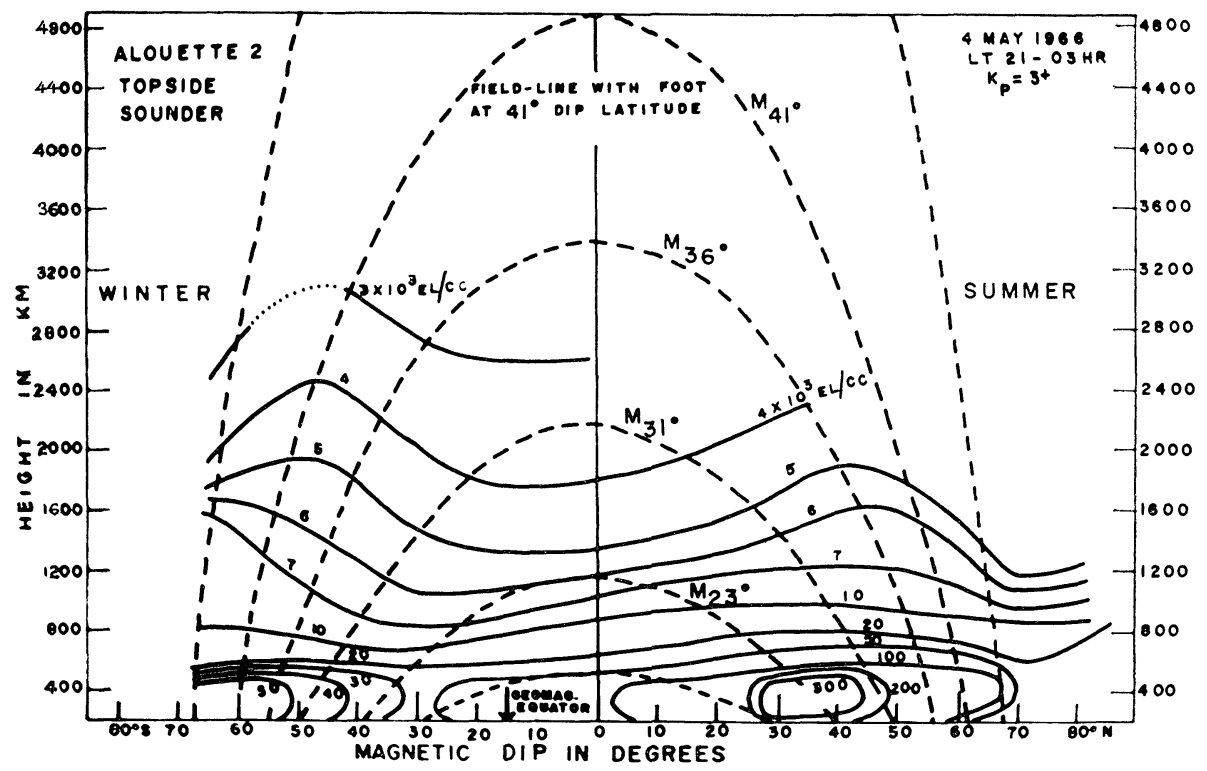

Fig. 2. Latitudinal contours of constant electron density and alignment of mid-latitude $N_{e}$ peak along the magnetic field lines $\mathrm{M}_{36}$ and $\mathrm{M}_{41}$.

$r=$ radial distance of point on field line,

$\theta=$ latitude of point on field line,

$r_{0}=$ radial distance of field line in equatorial plane.

The values of the full-line contours of constant electron density are shown by the numbers $3,4,5,6$ in units of $10^{3}$ electrons $\mathrm{cm}^{-3}$. The diagram suggests that the mid-latitude $N_{e}$ peaks are aligned along magnetic field tubes lying between $\mathbf{M}_{36}$ and $\mathbf{M}_{41}$, and that they would merge together over the equator in the vicinity of $4,000 \mathrm{~km}$. Again it is clear that the nighttime equatorial trough of ionisation gains prominence only at altitudes above $1,000 \mathrm{~km}$. There is marked asymmetry in ionisation between the summer and winter hemisphere at altitudes around $400 \mathrm{~km}$, but this evens out considerably above $1,000 \mathrm{~km}$.

The in situ electrostatic probe observations of electron density $N_{e}$ and electron temperature $T_{e}$ are utilised in Fig. 3. All the curves are for local midnight hours, but they occur in different longitude sectors. The lowermost curves of satellite altitude show that within $\pm 40^{\circ}$ dip latitude, the satellite altitude is around $2,500 \mathrm{~km}$ (with the exception of one pass) and hence changes in the ionisation pattern cannot arise from the height factor. The low-latitude trough of ionisation with $N_{e}$ peaks around $\pm 40^{\circ}$ dip latitude is very clear; the $N_{e}$ peaks appear to occur at the locations where $T_{e}$ commences its rise towards higher latitudes and $N_{e}$ itself starts decreasing towards the plasma trough. 


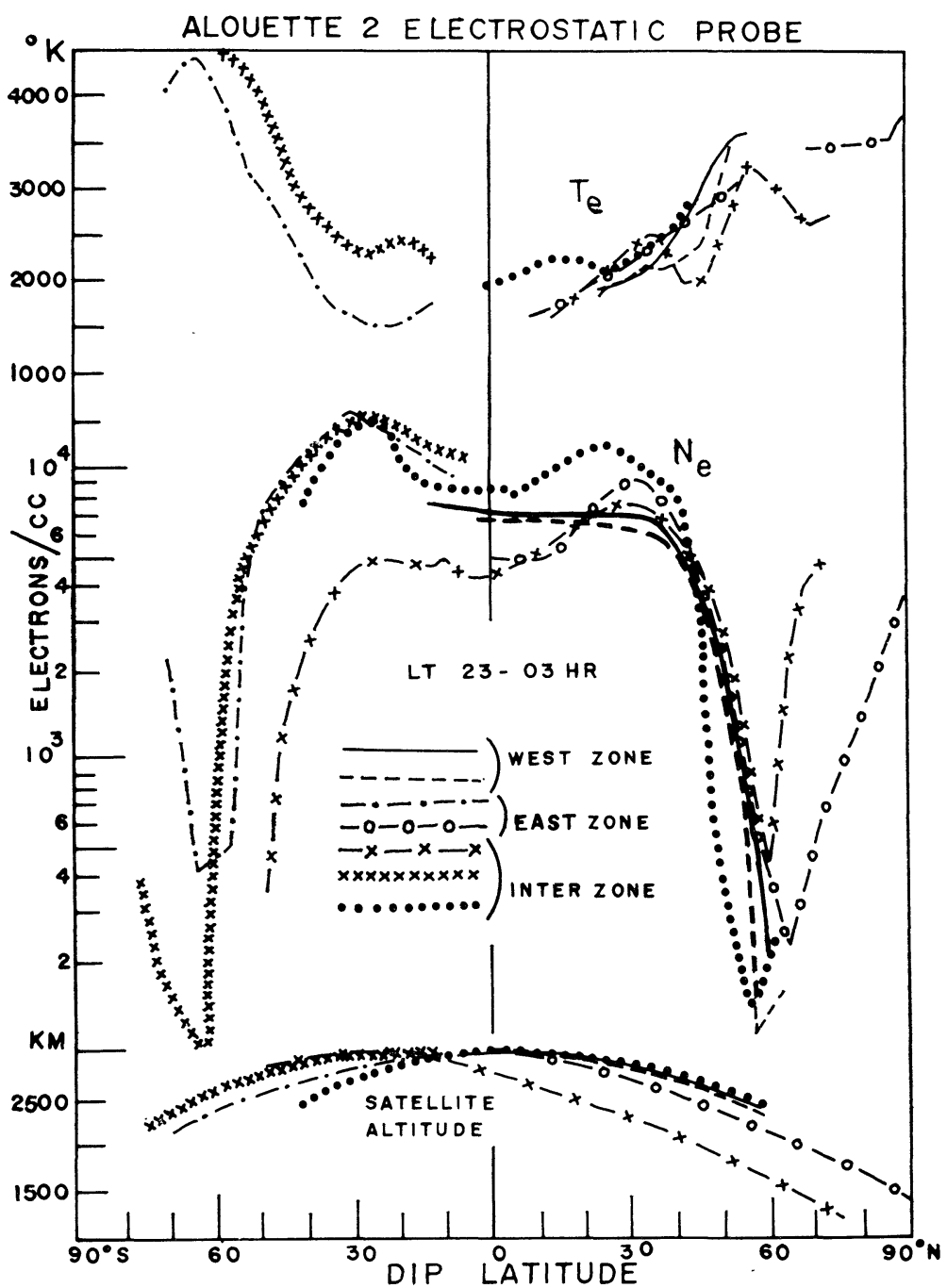

Fig. 3. Mid-latitude $N_{e}$ peaks observed by Alouette 2 electrostatic probe in various sectors in the night time hours, and the corresponding $T_{e}$ latitudinal variations.

The $N_{e}$ variations of Fig. 3 and other Alouette 2 passes examined showed a dependence of the $N_{e}$ peak formation on the longitude sector of observation. The equatorial trough and mid-latitude $N_{e}$ peak features showed most prominently in the East, i.e., Asia-Australia zone (130 to $250^{\circ} \lambda$ where $\lambda$ is the equatorial geomagnetic longitude). It was least pronounced in the West, i.e., American zone $\left(280\right.$ to $\left.40^{\circ} \lambda\right)$, and occupied intermediate values in the Inter, i.e., Europe-Africa zone $\left(30\right.$ to $\left.130^{\circ} \lambda\right)$. These observations are based on the $N_{e}$ 

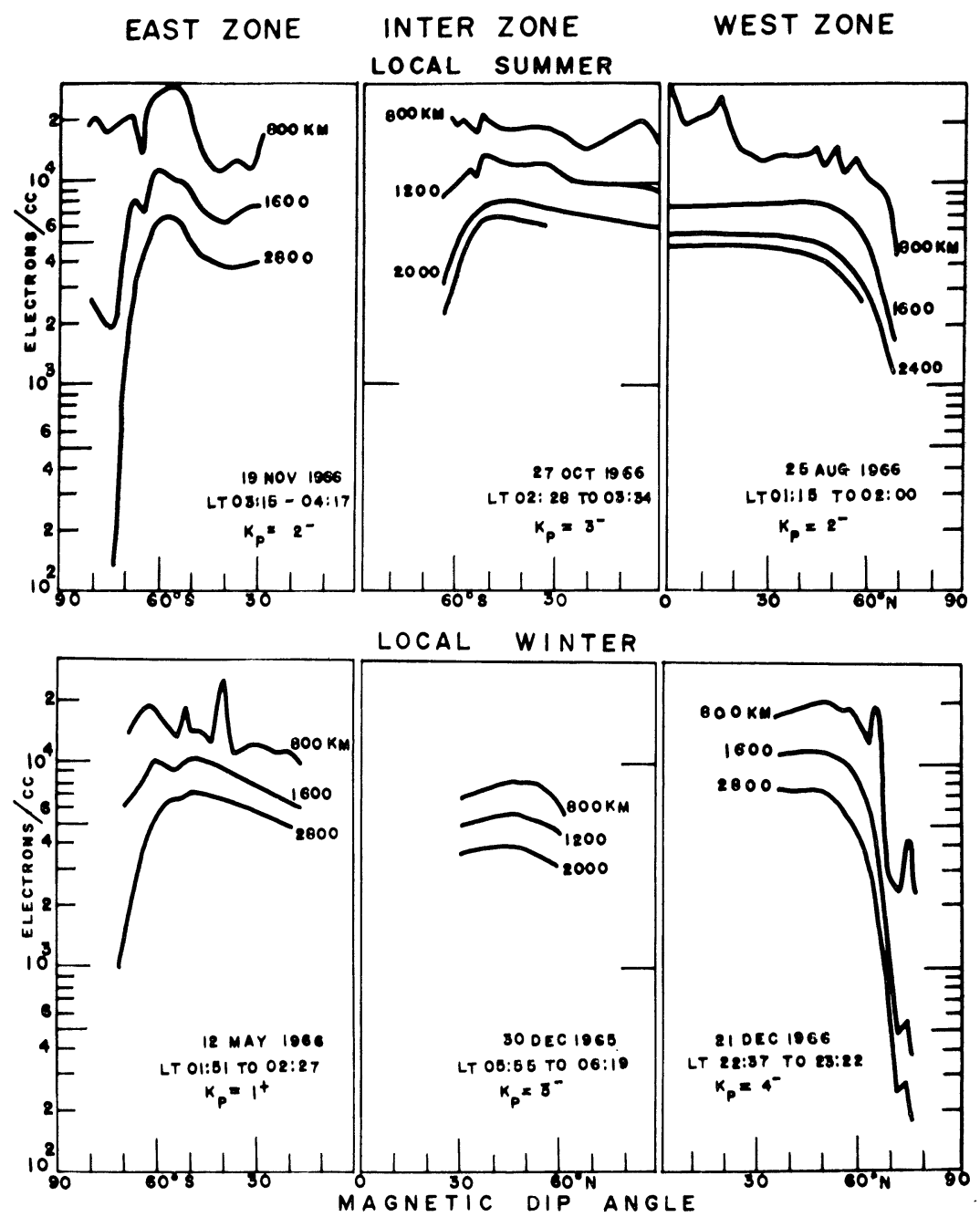

Fig. 4. Topside sounder observations of electron density at various altitudes ranging from 800 to $2,800 \mathrm{~km}$ in the various zones. For both local summer and local winter conditions, the $N_{e}$ mid-latitude peak is most prominent in the East zone.

variations shown in Fig. 4 from the topside sounder data over the different geographic sectors. All these passes are for the nighttime hours, the majority of them being for magnetically quiet intervals of quiet days. The latitudinal variation of electron density at representative heights, ranging from 800 to $2,800 \mathrm{~km}$ is shown by the curves. The $N_{e}$ peak at around $50^{\circ}$ dip is very marked in the East zone during both local summer and local winter months. For the 


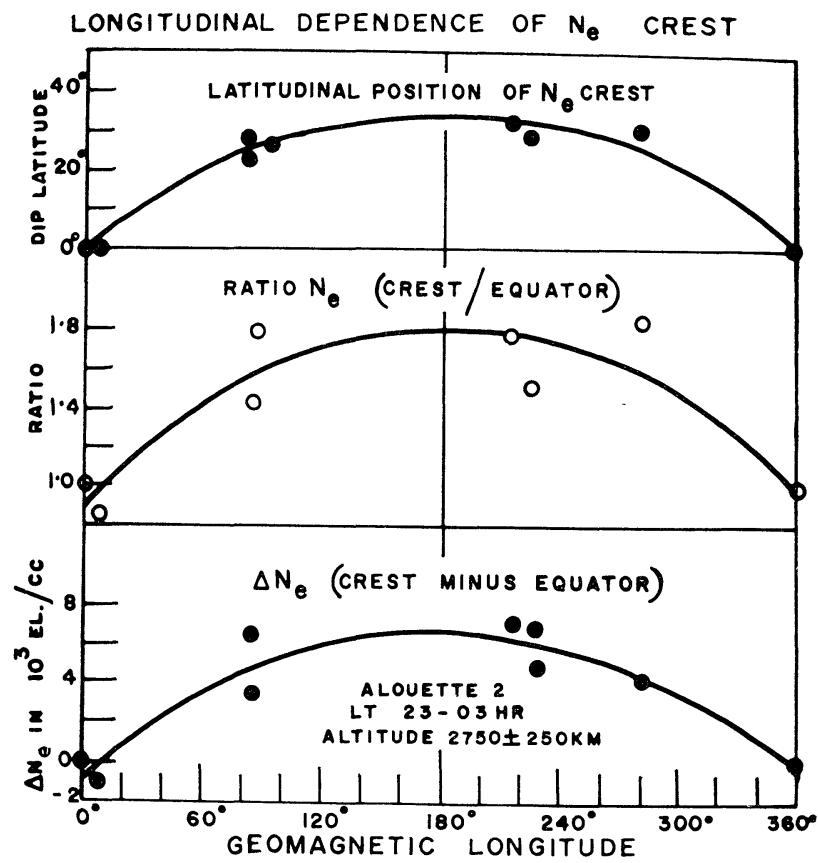

Fig. 5. Latitudinal position of the mid-latitude $N_{e}$ peak, and its intensity as compared to equatorial $N_{e}$, as a function of geomagnetic longitude during local midnight.

same local season, it is less pronounced in the Inter zone, and is almost absent in the West zone.

In view of this longitudinal effect on the $N_{e}$ peak, it was thought reasonable to plot the latitudinal position and intensity of the peak as a function of the equatorial geomagnetic longitude. Figure 5 shows the longitude dependence of the mid-latitude $N_{e}$ peak; in the upper curve is shown its location in dip latitude and the second curve expresses the ratio of the crest $N_{e}$ (value of $N_{e}$ at the midlatitude peak) to the trough $N_{e}$ (value of $N_{e}$ at the equator). The trend of the curves clearly suggests that the maximum of both parameters would occur in the vicinity of $180^{\circ} \lambda$. The local time of observation for all the points shown is around midnight hours.

The in situ electron density observed by the Alouette 2 probe, at $0,10,20$, 30 , and $40^{\circ}$ dip latitude during local midnight hours were also plotted as a function of geomagnetic longitude as shown in Fig. 6. The satellite altitude for these data remained in the vicinity of $2,500 \mathrm{~km}$. Using the information from Fig. 5, namely that the $N_{e}$ crest maximum is likely to be in the vicinity of $180^{\circ} \lambda$, sine curves are fitted to the data points for the different latitudes using 


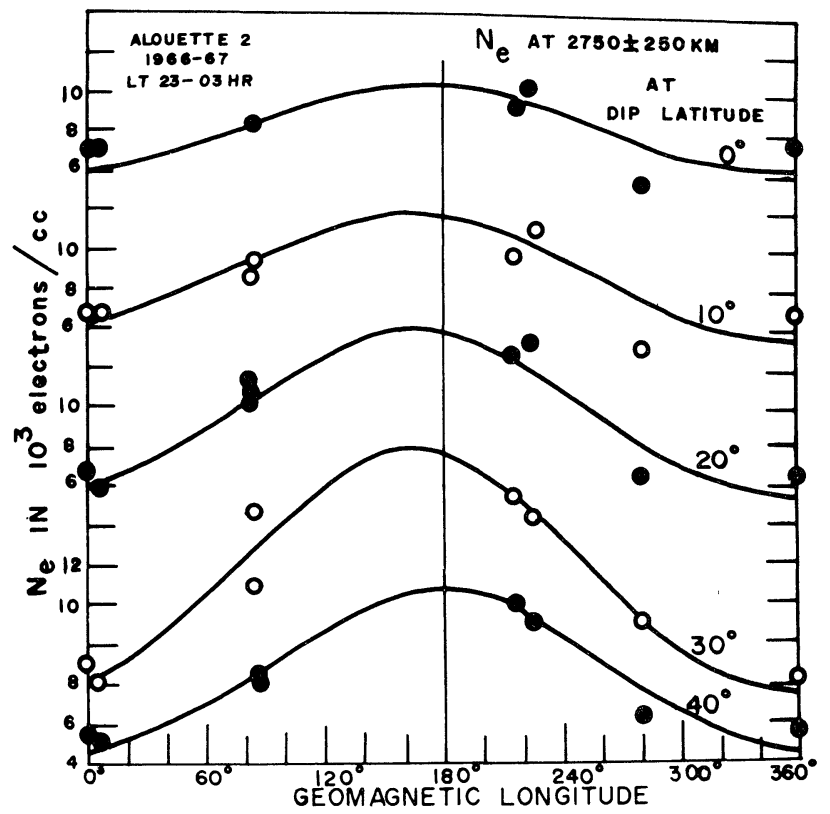

Fig. 6. Electron density at $0,10,20,30,40^{\circ}$ dip latitude, as a function $\approx$ of geomagnetic longitude during midnight hours for the altitude range $2,750 \pm 250 \mathrm{~km}$.

the method of least squares. At most latitudes, the best-fitting sine curve has its maximum at $160^{\circ} \lambda$. The curves show that for any latitude between 0 and $40^{\circ} \lambda$, namely in the entire low-latitude belt, the electron density at local midnight hours is largest in the vicinity of $180^{\circ} \lambda$ and smallest around $360^{\circ} \lambda$. Examined critically, the figure suggests that the largest electron densities occur at $30^{\circ}$ dip latitude.

Assuming symmetry about the dip equator, the global configuration of $N_{e}$ and $T_{e}$ during midnight hours for the low latitudes within $\pm 40^{\circ} \phi$ was obtained from the electrostatic probe observations at different longitudes. These contours correspond to the 2,500-3,000 km observations of the satellite, and are shown in Fig. 7; the units of $N_{e}$ are $10^{2} \mathrm{el} / \mathrm{cm}^{3}$ and those of $T_{e}$ are degrees Kelvin. The $N_{e}$ contours show a region of high electron density around $180^{\circ} \lambda$, with low values around 0 and $360^{\circ} \lambda$. The dashed line depicts the variation of maximum $N_{e}$ with geomagnetic longitude. The $T_{e}$ contours show considerable longitudinal asymmetry in electron temperature within $\pm 40^{\circ} \phi$. Two regions of low $T_{e}$ (less than $1,750 \mathrm{~K}$ ) are conspicuous at the 0 and $360^{\circ} \lambda$ low-latitude regions, corresponding to low values of $N_{e}$ in the upper contours. At latitudes beyond $\pm 40^{\circ}$ however, no marked longitudinal asymmetry is seen in the $T_{e}$ distribution. 


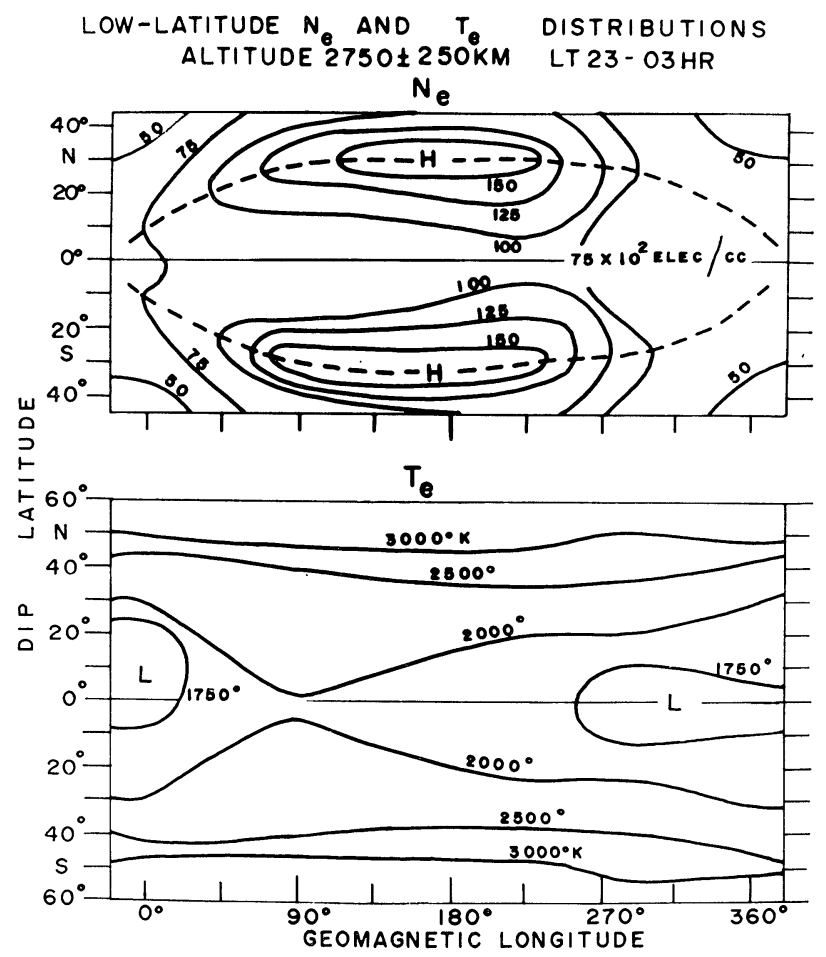

Fig. 7. Low-latitude configuration of $N_{e}$ and $T_{e}$ at altitudes $2,750 \pm 250 \mathrm{~km}$, as a function of geomagnetic longitude, during midnight hours.

\section{Discussion}

It appears that the formation of an equatorial trough in electron density, with its peaks at $\pm 40^{\circ} \phi$ is a characteristic of the nighttime exosphere above $1,000 \mathrm{~km}$. This feature is not to be confused with the equatorial $F$ region anomaly in the bottomside below $1,000 \mathrm{~km}$, in which by daytime a low-latitude trough of $N_{e}$ forms with crests at around $\pm 20^{\circ} \phi$. The nighttime equatorial trough discussed here gains prominence above $1,000 \mathrm{~km}$.

The gradual increase of ionisation from the equator to $40^{\circ} \phi$ at $2,500 \mathrm{~km}$ altitude suggests that the plasma in the protonospheric regions above $3,000 \mathrm{~km}$ flows down along the magnetic flux tubes by nighttime. For some reason, this field-aligned plasma flow maximises at $30^{\circ} \phi$, and fails to be effective in enhancing $N_{e}$ beyond $40^{\circ} \phi$. Since the plasma content of the geomagnetic field tube increases with the volume of the tube (PARK, 1972), it seems reasonable that the contribution from the region above $3,000 \mathrm{~km}$ will increase with geomagnetic latitude till plasma removal processes set in. 
The possibility of a field-aligned flow of thermal plasma from the nighttime protonosphere into the lower ionosphere was first pointed out by HANSON and Ortenburger (1961), and developed later by several workers (HANSON and Patterson, 1964; Geisler and Bowhill, 1965; Nagy et al., 1968; Moffett and Murphy, 1973). Park and Banks (1974) have solved the continuity and momentum equations for $\mathrm{H}^{+}$and $\mathrm{O}^{+}$with appropriate boundary conditions, using various working models of the thermosphere taken from Tables B of BANKS and KockARTS (1973). They clearly show that the nighttime protonosphere above $3,000 \mathrm{~km}$ is a thermal plasma reservoir, whose content is hardly depleted by plasma flow into other regions. For a mid-latitude magnetic field tube, a plasma flow of $5 \times 10^{8} \mathrm{ion} / \mathrm{cm}^{2} \mathrm{sec}$ sustained over $4 \mathrm{hr}$ depleted the tube plasma content by only $10 \%$. MARUBASHI and GrebowsKy (1976) also show that the time constant $N_{T} / F$ (where $N_{T}$ is the tube plasma content above 3,000 $\mathrm{km}$, and $F$ is the $\mathrm{H}^{+}$ion flux at $3,000 \mathrm{~km}$ for a given $\mathrm{H}^{+}$ion density at $3,000 \mathrm{~km}$ for nighttime hours) is $10^{5}$ to $10^{6} \mathrm{sec}$.

Apparently there is a critical value of $\mathrm{H}^{+}$ion density at $3,000 \mathrm{~km}$ (denoted by $\left.n\left(\mathrm{H}^{+}\right)_{3000}\right)$ which decides whether the $\mathrm{H}^{+}$plasma flow is upwards into the protonosphere or downwards into the ionosphere. This critical value is given by BANKs and DoupniK $(1974)$ as $9 \times 10^{3}$ ions $/ \mathrm{cm}^{3}$. When $n\left(\mathrm{H}^{+}\right)_{3000}$ is less than this value, the plasma flow is upwards into the protonosphere; for values exceeding this it is downwards into the ionosphere, with the magnitude of the flow increasing rapidly as $n\left(\mathrm{H}^{+}\right)_{3000}$ increases. The observations in this paper then can be explained by a field-aligned flow of thermal plasma from the region above $3,000 \mathrm{~km}$, into the lower regions between 0 and $30^{\circ} \phi$. The requirement of $n\left(\mathrm{H}^{+}\right)_{3000}$ exceeding the critical value of $9 \times 10^{3}$ ions $/ \mathrm{cm}^{3}$ for a downward plasma flow is satisfied, as the $N_{e}$ density in Fig. 3 shows values of 1 to $2 \times 10^{4}$ electrons $/ \mathrm{cm}^{3}$ at $2,500 \mathrm{~km}$; this of course is on the assumption of the plasma being electrically neutral and the major ion being $\mathrm{H}^{+}$. The OGO-4 observations of CHEN et al. (1973) clearly reveal an equatorial trough and enhancements of $\mathrm{H}^{+}$ion density at $\pm 40^{\circ} \phi$ during midnight hours very similar to the $N_{e}$ pattern seen in Fig. 3.

The observations of Fig. 2 also suggest that the mid-latitude $N_{e}$ peaks follow some specific field tubes which converge over the equator at around 4,000$5,000 \mathrm{~km}$, i.e., at almost $L=2$. This suggests the presence of a westward electric field at this altitude which gives rise to a cross $L$ drift of the magnetic field tubes through an $\boldsymbol{E} \times \boldsymbol{B}$ drift; this would enhance the plasma density in the concerned field tube. The origin of this westward electric field is still elusive. It seems presumptuous to associate this with the dawn to dusk convection electric field as normally one expects this only beyond the plasmapause at $L=4$. However the steep decrease in $N_{e}$ beyond $40^{\circ} \phi$ in the observations cited here suggests 
that the mechanism responsible for the formation of the mid-latitude plasmatrough starts from $L \approx 2$ itself.

Other workers have explored the effect of electric fields inside the plasmasphere on plasma flow. PARK and BAnKs (1974) show that for $n\left(\mathrm{H}^{+}\right)_{3000}$ of 1 or $2 \times 10^{4}$ ions $/ \mathrm{cm}^{3}$ there is an $\mathrm{H}^{+}$flux of 3 to $5 \times 10^{8}$ ions $/ \mathrm{cm}^{2} \mathrm{sec}$ downwards into the mid-latitude ionosphere, for zero electric field. In the presence of a westward electric field, the downward flux along the field tube increases in proportion to the intensity of the electric field; an eastward electric field tends to reduce the downward plasma flow. The model calculations of MARUBASHI and GREBOwSKY (1976) show that altitudes below $1,000 \mathrm{~km}$ are not affected by such electric fields; higher altitudes respond with a change in ion density, and plasma tube content above $3,000 \mathrm{~km}$ changes to some extent. Their work shows that the rate of change of the plasma tube content in a specific field tube due to the convection electric field is

$$
\frac{\partial}{\partial t} N_{T} \approx\left(\frac{L}{L_{\text {stag }}}\right)^{2} \omega N_{T}
$$

where

$L=L$ value of concerned field tube,

$L_{\text {stag }}=L$ value of stagnation point, generally at dusk with a quiet time value of 7 ,

$\omega=$ angular velocity of corotation in radians,

$N_{T}=$ plasma tube content above $3,000 \mathrm{~km}$ in ions/tube.

For $L=3.2$, and $N_{T} \approx 10^{13}$ ions/tube, Marubashi and Grebowsky (1976) show that the rate of change of $N_{T}$ is between $10^{8}$ to $10^{9} \mathrm{ions} / \mathrm{sec} /$ tube. Substitution of $L=2$ yields the rate of change to be $\approx 10^{8} \mathrm{ions} / \mathrm{sec} / \mathrm{tube}$. In either case this change in tube content almost matches the normal $\mathrm{H}^{+}$flux along the magnetic field tubes existing in the absence of electric field.

The strong geomagnetic longitude dependence shown by this $N_{e}$ peak feature also suggests that an $\boldsymbol{E} \times \boldsymbol{B}$ drift mechanism is involved in its formation. The vicinity of $180^{\circ} \lambda$ is the region where the earth's equatorial magnetic field has the largest intensity $(0.40$ Gauss $)$, while $0^{\circ} \lambda$ is the sector with the smallest equatorial field intensity ( 0.26 Gauss). Any phenomenon involving the equatorial field intensity would show a sharp contrast between the 0 and $180^{\circ} \lambda$ sectors as is suggested by the results in this paper.

The role played by $T_{e}$ in the formation of this $N_{e}$ peak is not clear and requires further study. Averaged values of nighttime $N_{e}$ at the $2,500 \mathrm{~km}$ altitude region suggest that the mid-latitude $N_{e}$ peak gains prominence in solstitial months and is flattened out in equinoctial months (RAJARAM and OBAYASHI, 1977). Some investigation is also required on the seasonal dependence of the $N_{e}$ 
peak. It appears that field-aligned diffusion of plasma from the protonosphere above $3,000 \mathrm{~km}$, together with a westward electric field in the region of $L \approx 2$ can cause the formation of this mid-latitude $N_{e}$ peak, and its geomagnetic longitude inequality.

The authors are thankful to Prof. A. Nishida of the Institute of Space and Aeronautical Sciences, University of Tokyo, Japan and to Prof. H. Oya of Tohoku University, Sendai, Japan for stimulating and critical discussions. Discussions with Prof. A.C. Das of PRL, Ahmedabad are gratefully acknowledged. They thank the World Data Centre A (Rockets and Satellites), GSFC, Greenbelt, USA, for making available the data used in this study.

One of us (Girija Rajaram) expresses deep gratitude to the Japan Society for the Promotion of Science for financial support; and to the Institute of Space and Aeronautical Sciences, University of Tokyo, Japan for the inspiring environment and the excellent working facilities provided throughout.

\section{REFERENCES}

BANKs, P.M. and J.R. Doupnik, Thermal proton flow in the plasmasphere: The morning sector, Planet. Space Sci., 22, 79-94, 1974.

Banks, P.M. and G. Kockarts, Aeronomy, Part B, p. 311, Academic Press, New York, 1973.

BRACE, L.H., B.M. REDdY, and H.G. MAYR, Global behaviour of ionosphere at 1,000 km altitude, J. Geophys. Res., 72, 265-283, 1967.

Chen, A.J., J.M. Grebowsky, and H.A. TAYlor, Jr., Light ion trough structure-A combination of orbital geometry and plasmasphere dynamics, presented at Chapman Memorial Symposium, Boulder, Colorado, June, 1973.

Geisler, J.E. and S.A. Bowhill, An investigation of ionosphere-protonosphere coupling, Aeron. Rep. 5, Univ. of Ill., Urbana, 1965.

Hanson, W.B. and I.B. Ortensurger, The coupling between the protonosphere and the normal $F$ region, J. Geophys. Res., 66, 1425-1435, 1961.

Hanson, W.B. and T.N.L. Patterson, The maintenance of the night-time $F$ layer, Planet. Space Sci., 12, 979-997, 1964.

Marubashi, K. and J.M. Grebowsky, A model study of diurnal behaviour of the ionosphere and the protonosphere coupling, J. Geophys. Res., 81, 1700-1706, 1976.

MatuURA, N. and T. ONDOH, The structure of the topside ionosphere deduced from Alouette data, Proc. IEEE, 57, 1150-1154, 1969.

Moffett, R.J. and J.A. MURPhy, Coupling between the $F$ region and protonosphere: Numerical solution of the time-dependent equations, Planet. Space Sci., 21, 43-52, 1973.

NAGy, A.F., P. BAUer, and E.G. Fontheim, Night-time cooling of the protonosphere, J. Geophys. Res., 73, 6259-6274, 1968.

PARK, C.G., Methods of determining electron concentrations in the magnetosphere from nose whistlers, Tech. Rep. 3454-1, Radio Sci. Lab., Stanford Univ., Stanford, Calif., 1972.

PARK, C.G. and P.M. BANKs, Influence of thermal plasma flow on the mid-latitude night-time $F_{2}$ layer: Effects of electric fields and neutral winds inside the plasmasphere, J. Geophys. Res., 79, 4661-4668, 1974. 